McGill University Health Center, Montreal, Canada

james.brophy@mcgill.ca Cite this as: BMJ 2020;370:m2797 http://dx.doi.org/10.1136/bmi.m2797 Published: 13 July 2020

\title{
US purchases world stocks of remdesivir: why the rest of the world should be glad to be at the back of the queue
}

The remdesivir story may actually be good news for the rest of the world, argues James $\mathbf{M}$ Brophy James M Brophy professor of medicine and epidemiology

On 30 June, the Guardian ran an article with the headline "US secures world stock of key covid-19 drug remdesivir," lamenting the monopolisation for "the next three months of one of the two drugs proven to work against covid-19, leaving none for the UK, Europe, or most of the rest of the world."1 This "me first" attitude should surprise nobody familiar with the current US administration's attitude towards anything involving international collaboration-such as its stance on climate change, the World Health Organization, trade, and immigration.

Paradoxically, the remdesivir story may actually be good news for the rest of the world. Let me elaborate. The evidence for remdesivir's clinical benefit is provided by a randomised controlled trial of 1063 patients published in the New England Journal of Medicine. It shows a shortened median time to recovery in the remdesivir group, compared with 15 days in the placebo group. ${ }^{2}$ There was no effect on mortality. Moreover, there are many reasons why the shortened reported time to symptomatic recovery may be an overestimate of its true value.

Firstly, let's recall some basic principles of controlled trials. It's been established that company sponsored trials, prematurely stopped trials, poorly executed trials with unsuccessful blinding, and large lost to follow-up trials all contribute to exaggerated, embellished, and unreliable effect measures. ${ }^{3-7}$ This remdesivir study was company sponsored, prematurely stopped, had incomplete blinding, and only about $15 \%$ of patients had their outcome determined at the specified primary endpoint of 28 days. An additional concern for some is the modification of the primary trial endpoint shortly before publication, although apparently before unblinding of any results. By contrast, a non-company sponsored trial looking at the same remdesivir doses found no benefit for either symptom duration or mortality. Are we still convinced about the magnitude of any potential benefit? ${ }^{8}$

Obviously, in a pandemic there is a strong push to quickly find efficacious treatments, but this becomes increasingly difficult when results are first presented, not in peer reviewed journals but in press conferences and preprints. Moreover, we must be aware of associated extra-scientific cognitive biases that can influence the clarity of our decision making. For example, when the leading US coronavirus expert describes the above mentioned study as showing "a clear cut, significant, positive effect in diminishing the time to recovery" the stage is set for optimism, confirmation, and group think biases that can impede an objective, critical, and comprehensive assessment of the totality of the evidence. ${ }^{9}$ These biases are exemplified in a quote in the Guardian article from Andrew Hill, senior visiting research fellow at Liverpool University, stating, "Remdesivir would get people out of hospital more quickly, reducing the burden on the NHS, and might improve survival," and, "Once again we're at the back of the queue."

I would argue that in this case, it is good to be at the back of the queue. It's worth repeating that no remdesivir study has demonstrated any reduction in hospital stay or mortality. Even ignoring the uncertainty about the magnitude of any reduction in symptomatic recovery time, it is far from obvious that reductions in length of hospital stay would follow. Most patients hospitalised with covid-19 are older with multiple comorbidities and often are frail with limited social support systems that may lead to a prolongation of hospital stay beyond the duration of their infectious symptoms. For this marginal and uncertain benefit, the manufacturer now proposes charging around \$3000 (£2400; €2700) per treatment. Remdesivir's history may also provoke additional reservations since its investigation as a treatment for other viral diseases, including hepatitis $\mathrm{C}$ and Ebola, has not demonstrated any clinical success. ${ }^{10}$ Also, the last time countries stockpiled billions of dollars' worth of antivirals-at least \$1obn for oseltamivir (Tamiflu) - could hardly be considered a success as it was eventually removed from WHO's list of essential drugs. ${ }^{11}$ The aphorism "Those who don't know history are doomed to repeat it” seems appropriate.

In conclusion, yes, the US action is truly the apotheosis of a self-centred nation, but it is potentially beneficial for other countries. Better to have the plutocratic American healthcare system dominate this market with an expenditure of $\$ 1.5 \mathrm{bn}$ for such uncertain benefits. The money other countries save can surely be better spent on further research for this and other drugs as well as for public health measures, including testing, contact tracing, and maintaining universal healthcare, all notable lacunae in the American system.

Competing interests: There are no relationships with industry. JMB is a research scholar supported by Les Fonds de Recherche Québec Santé.

\section{Commissioned, not peer reviewed.}

Bosely S. US secures world stock of key covid-19 drug remdesivir. Guardian 30 June 2020. www.theguardian.com/us-news/2020/jun/30/us-buys-upworld-stock-of-key-covid-19-drug.

Beigel JH, Tomashek KM, Dodd LE, et al. Remdesivir for the treatment of covid-19: preliminary report. N EnglJ Med2020 May 22;NEJMoa2007764. 
3 Gaudino M, Hameed I, Rahouma M, et al. Characteristics of contemporary randomized clinical trials and their association with the trial funding source in invasive cardiovascular interventions. JAMA Intern Med 2020;180:993-1001. doi: 10.1001/jamainternmed.2020.1670 pmid: 32478821

4 Lundh A, Sismondo S, Lexchin J, Busuioc OA, Bero L. Industry sponsorship and research outcome. Cochrane Database Syst Rev 2012;12:pmid: 23235689

5 Bassler D, Briel M, Montori VM, et alSTOPIT-2 Study Group. Stopping randomized trials early for benefit and estimation of treatment effects: systematic review and meta-regression analysis. JAMA 2010;303:1180-7. doi: 10.1001/jama.2010.310 pmid: 20332404

6 Schulz KF, Chalmers I, Hayes RJ, Altman DG. Empirical evidence of bias. Dimensions of methodological quality associated with estimates of treatment effects in controlled trials. JAMA 1995;273:408-12. doi: 10.1001/jama.1995.03520290060030 pmid: 7823387

7 AkI EA, Briel M, You J, et al. Potential impact on estimated treatment effects of information lost to follow-up in randomised controlled trials (LOST-IT): systematic review. BMI2012;344:. doi: 10.1136/bmj.e2809 pmid: 22611167

8 Wang Y, Zhang D, Du G, et al. Remdesivir in adults with severe COVID-19: a randomised, double-blind, placebo-controlled, multicentre trial. Lancet 2020;395:1569-78. doi: 10.1016/S0140-6736(20)31022-9 pmid: 32423584

9 Edwards E. Remdesivir shows promising results for coronavirus, Fauci says. NBC News. 29 April 2020. www.nbcnews.com/health/health-news/coronavirus-drugremdesivir-shows-promise-large-trial-n1195171.

10 Mulangu S, Dodd LE, Davey RTJr, et alPALM Writing GroupPALM Consortium Study Team. A randomized, controlled trial of Ebola virus disease therapeutics. NEngl/Med 2019;381:2293-303. doi: 10.1056/NEJMoa1910993 pmid: 31774950

11 Ebell MH. WHO downgrades status of oseltamivir. BMJ2017:358:3266. doi: 10.1136/bmi.j3266 pmid: 28701339 